Check for updates

Cite this: RSC Adv., 2019, 9, 2189

Received 7th November 2018

Accepted 23rd December 2018

DOI: $10.1039 / c 8 r a 09193 e$

rsc.li/rsc-advances

\section{Effects of blending sequences and molecular structures of the compatibilizers on the morphology and properties of PLLA/ABS blends}

\author{
Xiaojun Cao, Wenyong Dong, (D)* Meifeng He, Junqing Zhang, Fanglu Ren \\ and Yongjin Li (iD)*
}

\begin{abstract}
The effects of molecular structures of the compatibilizers and blending sequences on the morphology and properties of the immiscible poly(L-lactide)/acrylonitrile-butadiene-styrene (PLLA/ABS) blend are investigated herein. The comb-like polymers $(R C)$, which are constituted by a poly(methyl methacrylate) (PMMA) backbone and side chains and a few epoxy groups distributed randomly along the backbone, are found to be better compatibilizers for improving the morphology and mechanical properties of the PLLA/ABS blend, compared to linear polymers (RL) constituted by a PMMA backbone and epoxy groups along the backbone. In addition, the blending sequence, which dictates the extent of grafting reaction between carboxyl end groups of PLLA and epoxy groups in the RL and RC compatibilizers, is found to influence the diffusion and location of the in situ formed RL-g-PLLA and RC-g-PLLA polymers in the blend system. By blending RL or RC polymers with ABS phase firstly, the epoxy groups are diluted by ABS phase; thus, during the second step, blending with PLLA phase, lightly grafted polymers are formed. This method is found to be the best sequence to compatibilize the PLLA/ABS system. When the PLLA phase is mixed with the compatibilizers firstly, the highly grafted polymers are prone to be trapped in the PLLA phase, because the PMMA segments are shielded by the densely grafted PLLA segments from interacting efficiently with the ABS phase, and thus the morphology and mechanical properties of the blend deteriorate accordingly.
\end{abstract}

\section{Introduction}

It is well known that poly(L-lactide) (PLLA) is an inherently brittle polymer, which inevitably limits its applications in some areas, such as packaging, textile and composite materials. ${ }^{1,2}$ To improve the mechanical properties and reduce the price of PLLA, blending with other petroleum or bio-based polymers is an efficient method and has attracted a lot of attention during the past few years. ${ }^{3-7}$

Considering both economical and technical aspects, blending PLLA with a moderate amount of petroleum-based polymers is more feasible for commercial applications such as packaging; a tiny amount of compatibilizers, whether premade or in situ formed, is often designed and applied in these systems because of the thermodynamic immiscibility of PLLA/ petroleum-based polymer pairs. Hillmyer's group designed, synthesized and reported a series of block copolymers poly(Llactide)- $b$-polyethylene (PLLA- $b$-PE) with distinct molecular structures to compatibilize the PLLA/PE system, finding that the

College of Material, Chemistry and Chemical Engineering, Hangzhou Normal University, No. 16 Xuelin Road, Hangzhou 310036, P. R. China. E-mail: wenyong. dong@gmail.com; yongjin-li@hznu.edu.cn; Fax: +86-571-2886-7899; Tel: +86-5712886-7206 mechanical properties of the obtained PLLA composites correlate with the modulus of the dispersed PE phase and the interfacial adhesion, which is dictated by the molecular structures of the PLLA-b-PE block copolymers. ${ }^{8,9}$ They also applied a commercial ethylene-glycidyl methacrylate-methyl acrylate terpolymer (PEGMMA) to compatibilize the poly(L-lactide)/ polypropylene (PLLA/PP) or poly(L-lactide)/polypropylenebased elastomer (PLLA/PBE) system; they found that PEGMMA reduced the size of the dispersed PBE phase more effectively and yielded more ductile PLLA composite materials, compared to the system with PP as the dispersed phase. ${ }^{10}$ Blending PLLA with a moderate amount of petroleum-based elastomers was also considered by some researchers. Both Oyama $^{11}$ and Deng et al. ${ }^{12}$ successfully prepared super-tough PLLA blends by blending PLLA with reactive ethylene-acrylic ester-glycidyl methacrylate terpolymer (EGMA), and they found that the mechanical properties and thermal stabilities could be further enhanced by improving the crystallization of the PLLA matrix. Zeng et al. developed a series of novel supertough poly(L-lactide)/polyurethane (PLLA/PU) blends by adjusting the crosslinking density of in situ formed PU and controlling the feed ratios of the component monomers. ${ }^{13}$ They further applied the biomass-derived castor oil to react with the isocyanate monomer to form the PU phase, which proved to be a facile 
and cost-effective method compared to the previous reports on toughening PLLA using castor oil derivatives. ${ }^{14}$ Bai et al. reported a novel PLLA/elastomer blend with both super toughness and high heat resistance by blending ethylene-acrylic esterglycidyl methacrylate (EMA-GMA) with a moderate amount of poly(D-lactide) (PDLA) firstly, then with PLLA. The grafted PDLA side chains collaborated with the PLLA phase to form the stereocomplex (sc) crystallites at the interfacial region, which improved the strength of interfacial adhesion and enhanced the crystallinity of PLLA matrix simultaneously. ${ }^{15}$ They further applied a similar strategy to introduce a small amount of PDLA into the poly(L-lactide)/thermoplastic polyurethane (PLLA/TPU) system and successfully fabricated a super-toughened and heat-resistant PLLA/TPU blend. ${ }^{16}$

Improving the compatibilization efficiency is always a key point in reactive compatibilization. Some factors, such as molecular weight and structures of the compatibilizers, ${ }^{17-23}$ as well as the amount, type and distribution of the reactive groups in the compatibilizers, ${ }^{24-29}$ have been thoroughly investigated by some researchers. Blending sequence, which significantly influences the kinetics of interfacial reactions in reactive compatibilization, was also applied to improve the compatibilization efficiency and manipulate the morphology of the obtained blend..$^{30-43}$ Hale et al. found that the low-temperature and roomtemperature mechanical properties of the poly(butylene terephthalate)/acrylonitrile-butadiene-styrene (PBT/ABS) blends compatibilized by methyl methacrylate-glycidyl methacrylateethyl acrylate terpolymers (MGE) correlated tightly with the blending sequence. ${ }^{30}$ Lee et al. indicated that the morphologies of the blends were determined not only by some general factors such as viscosity ratios of the components and interfacial tension between two polymers, but also by melting sequences of the components and reaction rates of the functional groups; considering these interrelated factors, an appropriate blending sequence was required to optimize the compatibilization of the immiscible blends. ${ }^{31}$ Herein, ABS, which has been successfully reported to toughen some petroleum-based polyester systems such as polyethylene terephthalate (PET) and $\mathrm{PBT}^{\mathbf{4 4 , 4 5}}$ was applied to blend the bio-based PLLA system. The obtained PLLA/ABS blends could, on one hand, reduce the use of petroleum-based polymers and, on the other hand, have potential applications in commodity packaging, disposable tableware and automotive industries. Two kinds of PMMA-type $\mathrm{RL}$ and RC polymers were applied as compatibilizers in this system. RL and RC were synthesized by copolymerizing methyl methacrylate (MMA) and glycidyl methacrylate (GMA) without or with the MMA macromer, respectively. Some factors, including blending sequence and molecular structures of the compatibilizers, were investigated in detail for their effects on the morphology and the mechanical properties of the obtained blends.

\section{Experimental section}

\section{Materials}

PLLA used in this work was from Nature works (USA), with $M_{\mathrm{n}}$ of $90000 \mathrm{~g} \mathrm{~mol}^{-1}$ and $M_{\mathrm{w}} / M_{\mathrm{n}}$ of 1.8. ABS in this work was from LG Chemical (Korea), with $M_{\mathrm{n}}$ of $42000 \mathrm{~g} \mathrm{~mol}^{-1}$ and $M_{\mathrm{w}} / M_{\mathrm{n}}$ of 1.79 . The lab-made compatibilizers (RC and RL polymers) were synthesized as follows. ${ }^{46}$ Methyl methacrylate (MMA) macromer $\left(M_{\mathrm{n}}=4800 \mathrm{~g} \mathrm{~mol}^{-1}\right.$ and $\left.M_{\mathrm{w}} / M_{\mathrm{n}}=2.0\right)$, glycidyl methacrylate (GMA), and MMA were copolymerized at a weight ratio of $1 / 2 / 7$; thus the obtained polymers $\left(M_{\mathrm{n}}=40000 \mathrm{~g} \mathrm{~mol}^{-1}\right.$ and $M_{\mathrm{w}} / M_{\mathrm{n}}=$ 1.8) had a comb-like structures, which were constituted by PMMA backbone and side chains, with some epoxy groups distributing randomly along the backbone. By directly copolymerizing GMA with MMA at a weight ratio of $2 / 8$, RL polymers $\left(M_{\mathrm{n}}=32000 \mathrm{~g} \mathrm{~mol}^{-1}\right.$ and $\left.M_{\mathrm{w}} / M_{\mathrm{n}}=1.8\right)$ exhibiting a linear structure were obtained.

\section{Sample preparation}

As shown in Table 1, PLLA, ABS and the compatibilizers (RL and RC polymers) were mixed by three methods with different blending sequences. The blending temperature and rotation

Table 1 Blending sequences and the effect on perimeter/area

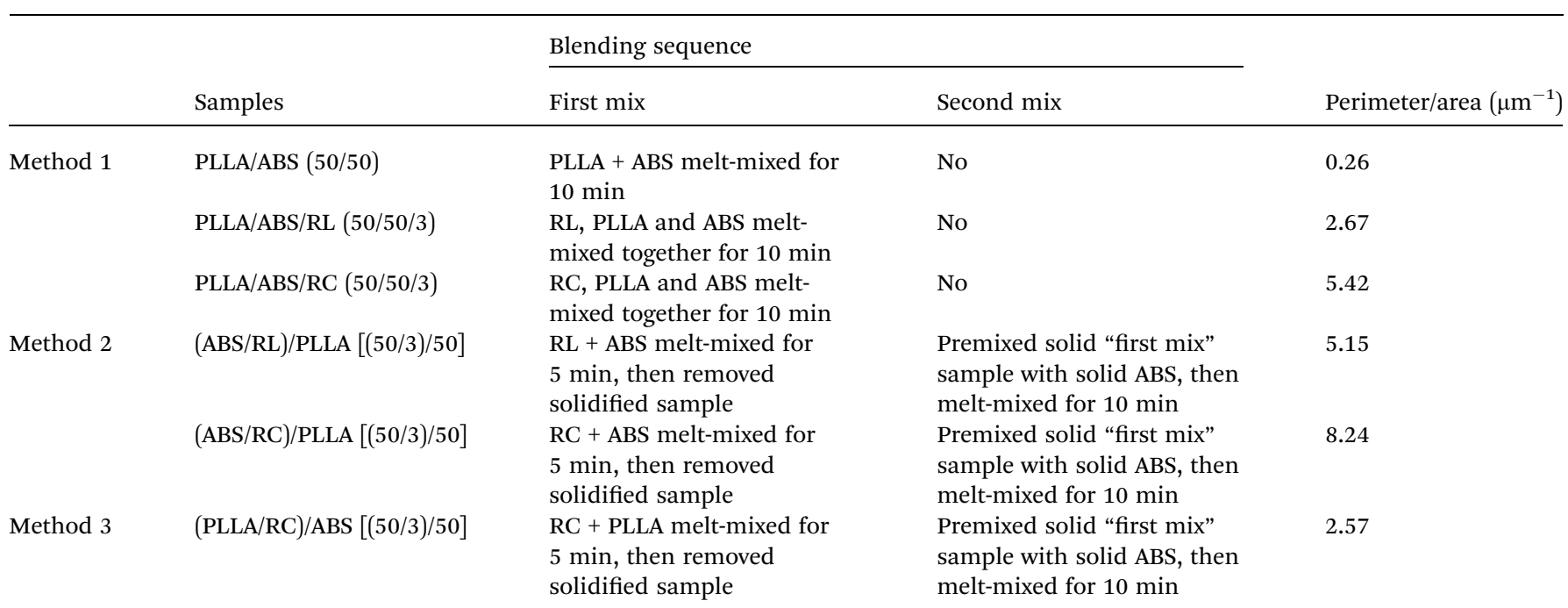


speed were set to $190{ }^{\circ} \mathrm{C}$ and $50 \mathrm{rpm}$, respectively. The weight ratio of ABS/PLLA was fixed at 50/50 for all the blends, and the amount of RL or RC polymers was fixed at $3 \mathrm{wt} \%$, based on the total weight of PLLA and ABS. For Method 1, all components, PLLA and ABS, with or without RL or RC, were simultaneously added and mixed in the HAAKE mixer for $10 \mathrm{~min}$. The final obtained blends were designated PLLA/ABS (50/50), PLLA/ABS/ RL (50/50/3) and PLLA/ABS/RC (50/50/3), respectively. For Method 2, ABS was premixed with RL or RC for $5 \mathrm{~min}$. The obtained blends (ABS/RL) or (ABS/RC) were then mixed with PLLA for $10 \mathrm{~min}$. The final obtained blends were designated (ABS/RL)/PLLA [(50/3)/50] and (ABS/RC)/PLLA [(50/3)/50], respectively. For Method 3, PLLA was firstly mixed with RC for $5 \mathrm{~min}$, and the obtained blend (PLLA/RC) was then mixed with ABS for $10 \mathrm{~min}$. The final obtained blend was designated as (PLLA/RC)/ABS [(50/3)/50]. The torque values of the blends and the components during processing were monitored and recorded by the HAAKE PolySoft software. The obtained blending samples were then pressed by a Qien compression molder into sheets with a thickness of $0.5 \mathrm{~mm}$ under $10 \mathrm{MPa}$ for $6 \mathrm{~min}$ at a pressing temperature of $190{ }^{\circ} \mathrm{C}$, then the sheets were cooled to room temperature by circulating water.

\section{Characterization}

Transmission electron microscopy (TEM). Ultrathin sections ( $\sim 70 \mathrm{~nm}$ thick) for TEM analysis were microtomed from the initial pressed sheets using a Leica EM UC7 ultramicrotome with a diamond knife at room temperature. The ultrathin sections were then collected on copper meshes (200\#) and stained with $\mathrm{RuO}_{4}$ for about 1 hour. A Hitachi HT-7700 TEM was used to characterize the morphologies of the PLLA/ABS blends at a voltage of $100 \mathrm{kV}$. The calculations of interface perimeter per unit area (perimeter/area) on the TEM images were carried out using the NIH image software. ${ }^{47}$

Differential scanning calorimetry (DSC). The thermal behaviors of the neat components and the PLLA/ABS blends were investigated by DSC (Q2000, TA instruments). Samples (about $10 \mathrm{mg}$ ) were heated from -50 to $220{ }^{\circ} \mathrm{C}$ at a heating rate of $10{ }^{\circ} \mathrm{C} \mathrm{min}{ }^{-1}$ under nitrogen, kept at $220^{\circ} \mathrm{C}$ for $5 \mathrm{~min}$ to erase the thermal history, then cooled to $-50{ }^{\circ} \mathrm{C}$ at a rate of $10{ }^{\circ} \mathrm{C} \min ^{-1}$ and finally heated to $220{ }^{\circ} \mathrm{C}$ at $10{ }^{\circ} \mathrm{C} \mathrm{min}{ }^{-1} . T_{\mathrm{g}}$ (glass transition temperature) and $T_{\mathrm{m}}$ (melting temperature) were determined from the second heating, while $\Delta H_{\mathrm{m}}$ (heat of fusion) was from the first heating.

Tensile test. An Instron universal material testing system (model 5966) was employed to measure the mechanical properties of the PLLA/ABS blends at $23^{\circ} \mathrm{C}$ and a crosshead speed of $10 \mathrm{~mm} \mathrm{~min}^{-1}$. Dumbbell-shaped samples with gauge lengths of $18 \mathrm{~mm}$, widths of $3 \mathrm{~mm}$, and thicknesses of $0.5 \mathrm{~mm}$ were punched out from the initial pressed sheets.

Small-amplitude oscillatory shear (SAOS). The rheological behaviors of the neat components and the blends were characterized by a Physica rheometer (MCR301, Anton Paar Instrument) at $200{ }^{\circ} \mathrm{C}$ in a nitrogen atmosphere. A parallel plate configuration was used, with a plate diameter of $25 \mathrm{~mm}$ and a gap size of $0.5 \mathrm{~mm}$. Frequency sweep was carried out from 500 to $0.01 \mathrm{rad} \mathrm{s}^{-1}$ at a strain of 0.05 in the linear viscoelastic region.

\section{Results and discussion}

\section{Rheological measurements}

Torque rheometry was firstly applied to investigate the melt properties of neat components and the uncompatibilized and compatibilized PLLA/ABS blends produced by different blending sequences. As shown in Fig. 1, ABS is much more viscous than PLLA, and the torque curve of the uncompatibilized PLLA/ABS blend lies in between those of the neat components and closer to that of PLLA. Generally speaking, the epoxy groups in the RL and RC polymers are able to react with the carboxyl end groups of PLLA to form grafted polymers, RL- $g$ PLLA and RC- $g$-PLLA, respectively. In addition, crosslinking reaction can potentially occur among the epoxy groups. All of these factors will contribute a positive increment of torque
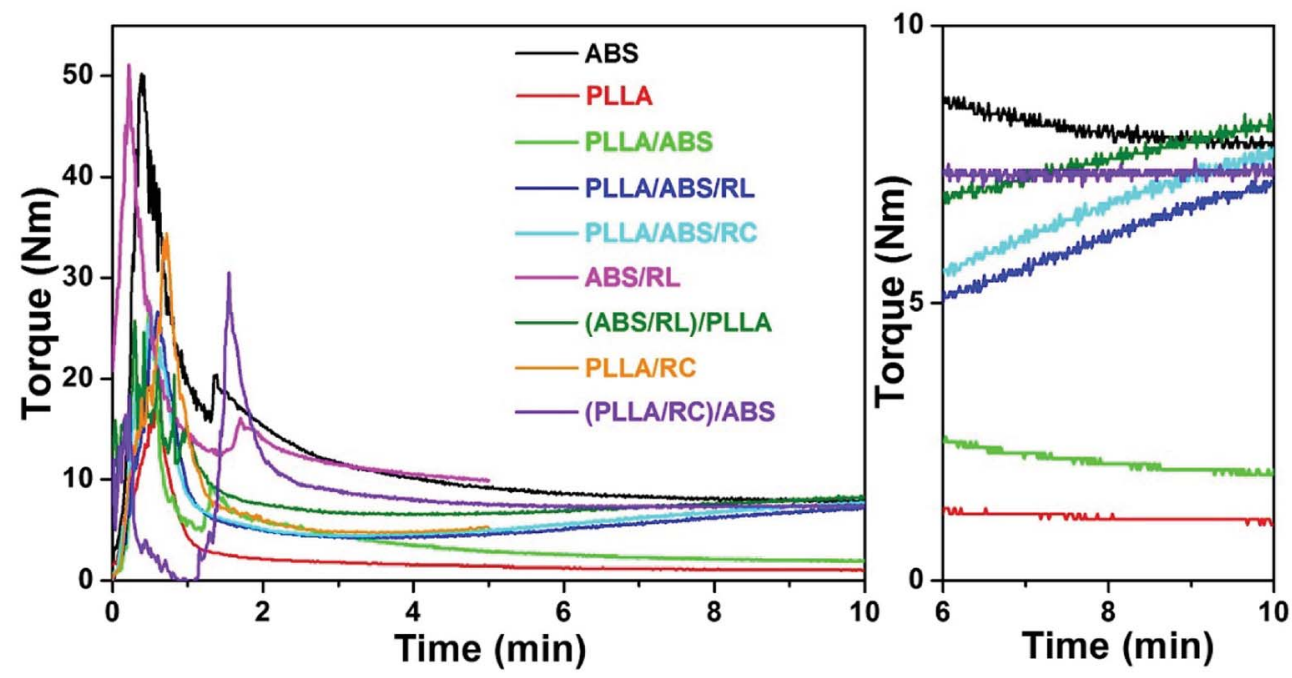

Fig. 1 Torque-time curves of the blends and blend components. An expanded view from 6 to 10 min is included on the right image. 


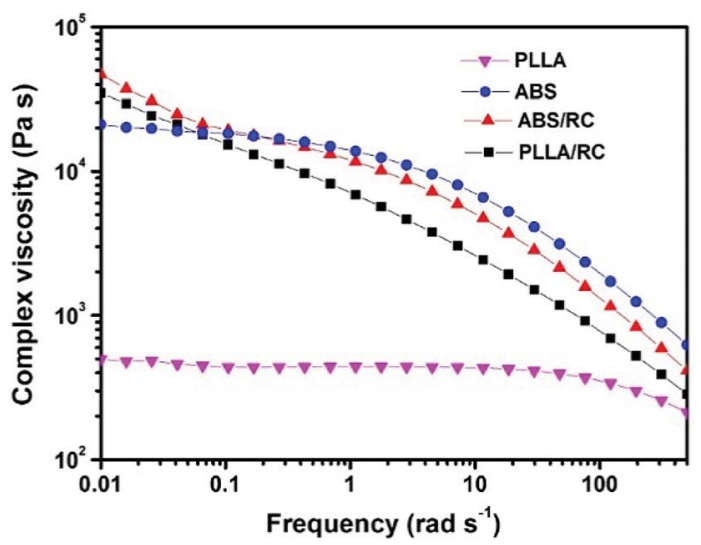

Fig. 2 Complex viscosity versus frequency for binary blends and blend components.

curves during reactive blending. It can be observed that for Method 1, the torque curve of the PLLA/ABS blend compatibilized with the RC polymer (i.e. PLLA/ABS/RC) exhibits a slightly higher level of torque value than the blend with RL polymer (i.e. PLLA/ABS/RL). For Method 2, the torque value of the premixed blend $\mathrm{ABS} / \mathrm{RL}$ is a little higher than that of neat $\mathrm{ABS}$ after blending for $5 \mathrm{~min}$, which indicates the occurrence of crosslinking reaction of the epoxy groups in the compatibilizers. With further blending with PLLA, the torque value becomes higher than that for Method 1, i.e., PLLA/ABS/RL. For Method 3, the torque value of the premixed blend PLLA/RC increases gradually with time, which confirms the reaction between the epoxy groups of the compatibilizers and the carboxylterminated groups of PLLA, and thus the formation of the grafted polymer RC- $g$-PLLA. Furthermore, when the premixed PLLA/RC is blended with ABS, the torque curve of the obtained (PLLA/RC)/ABS blend levels off after melting. Considering both the molecular structures and blending sequences, it should be noted that the torque level after $10 \mathrm{~min}$ of mixing is PLLA/ABS/ $\mathrm{RL}<(\mathrm{PLLA} / \mathrm{RC}) / \mathrm{ABS}<\mathrm{PLLA} / \mathrm{ABS} / \mathrm{RC}<(\mathrm{ABS} / \mathrm{RL}) / \mathrm{PLLA}$. It is well known that the morphology of the blend is correlated tightly with the viscosity of the components. Therefore, SAOS rheology was further performed to investigate the viscosity of the premixed blends produced by different blending sequences. As shown in Fig. 2, neat PLLA displays a Newtonian behavior over almost the entire frequency range, and the viscosity of the premixed blend PLLA/RC is significantly higher than that of neat PLLA, on account of the formation of the more viscous grafted polymer RC-g-PLLA. It is interesting to note that at low frequency, the viscosity of the ABS/RC blend is higher than that of the neat $\mathrm{ABS}$, while at higher frequency, the viscosity is a little lower than that of neat ABS, which reveals the existence of the crosslinking reaction in Method 2, which blends ABS and the compatibilizers firstly.

\section{Phase morphology investigations}

The uncompatibilized PLLA/ABS (50/50) blend exhibits a coarse morphology, in which the PLLA phase displays white and the SAN phase and the rubber phase of ABS appear grey and black, respectively, mainly due to the different speeds of staining. As mentioned above, the ABS phase is much more viscous than the PLLA phase; thus, the dispersive force of the PLLA phase is too low to obtain a fine morphology. For Method 1, when all the components are mixed together, as shown in Fig. 3(B and C), both the obtained blends compatibilized by RL and RC exhibit a co-continuous morphology, and the blend compatibilized by RC exhibits a much finer morphology than that by RL. As shown in Table 1, the value of perimeter/area increases from $0.26 \mu \mathrm{m}^{-1}$ in the uncompatibilized PLLA/ABS (50/50) blend to $2.67 \mu \mathrm{m}^{-1}$ in the PLLA/ABS/RL (50/50/3) blend and, finally, to $5.42 \mu \mathrm{m}^{-1}$ in the PLLA/ABS/RC (50/50/3) blend. For Method 2, as shown in Table 1 and Fig. 3(D and E), compared to Method 1, the obtained blends exhibit much finer co-continuous morphologies; the value of perimeter/area increases from 2.67 to $5.15 \mu \mathrm{m}^{-1}$ for the PLLA/ABS blend compatibilized by RL and from 5.42 to 8.24 $\mu \mathrm{m}^{-1}$ for the blend compatibilized by RC, respectively. For Method 3, as shown in Fig. 3(F), the blend exhibits a coarse morphology, and the value of perimeter/area decreases to 2.57 $\mu \mathrm{m}^{-1}$. The morphological variation with the molecular structures and the blending sequences can be ascribed to the different interfacial behaviors of the compatibilizers and the different viscosity ratios of the components.

The average shear rate of the internal mixer can be roughly estimated to be the rotation speed, which is $50 \mathrm{~s}^{-1} .{ }^{48} \mathrm{At} 50 \mathrm{~s}^{-1}$, the viscosity ratios of $\eta^{*}(\mathrm{ABS} / \mathrm{RC}) / \eta^{*}$ (PLLA) and $\eta^{*}(\mathrm{ABS}) /$ $\eta^{*}$ (PLLA/RC) are 5.3 and 2.5 , respectively. This means that premixing PLLA with the compatibilizer RC significantly increases the viscosity of the PLLA/RC phase; thus, the viscosity ratio of $\eta^{*}(\mathrm{ABS}) / \eta^{*}(\mathrm{PLLA} / \mathrm{RC})$ is much closer to unity, compared to Method 2 (premixing ABS with compatibilizer RC, then with PLLA). It can be anticipated that the blend with viscosity ratio much closer to unity will have a much finer morphology. ${ }^{49}$ However, it is obvious that Method 2 is more beneficial for the formation of much finer morphology. This indicates that the compatibilizing effect of in situ formed RC- $g$-PLLA plays a more important role in the morphology of the PLLA/ABS blend than the factor of viscosity ratio.

The PMMA-type compatibilizers are thermodynamically miscible with the SAN phase of ABS, as reported by some researchers, and the epoxy groups in RL or RC compatibilizers were able to react with the carboxyl end groups of PLLA. Undoubtedly, the different blending sequences will inevitably result in different extents of reaction between epoxy and carboxyl groups. When the compatibilizers are directly mixed with PLLA and ABS phase by Method 1, there actually exists an almost equal competition between the compatibilizers entering the ABS phase and reacting with the PLLA phase. For Method 2, by mixing ABS with compatibilizer RL or RC firstly, the concentration of the epoxy groups is diluted by the ABS phase, and thus only the epoxy groups, which are close enough to the interface, have an opportunity to react with PLLA, and lightly grafted RL-g-PLLA or RC-g-PLLA polymers are consequently formed, as shown in Scheme 1. In Method 3, premixing RC with PLLA phase, the epoxy groups have sufficient opportunities to react with PLLA, and thus highly grafted RC-g-PLLA polymers are formed. The extent of reaction between GMA groups of compatibilizers and PLLA can be deduced to be Method $3>$ 


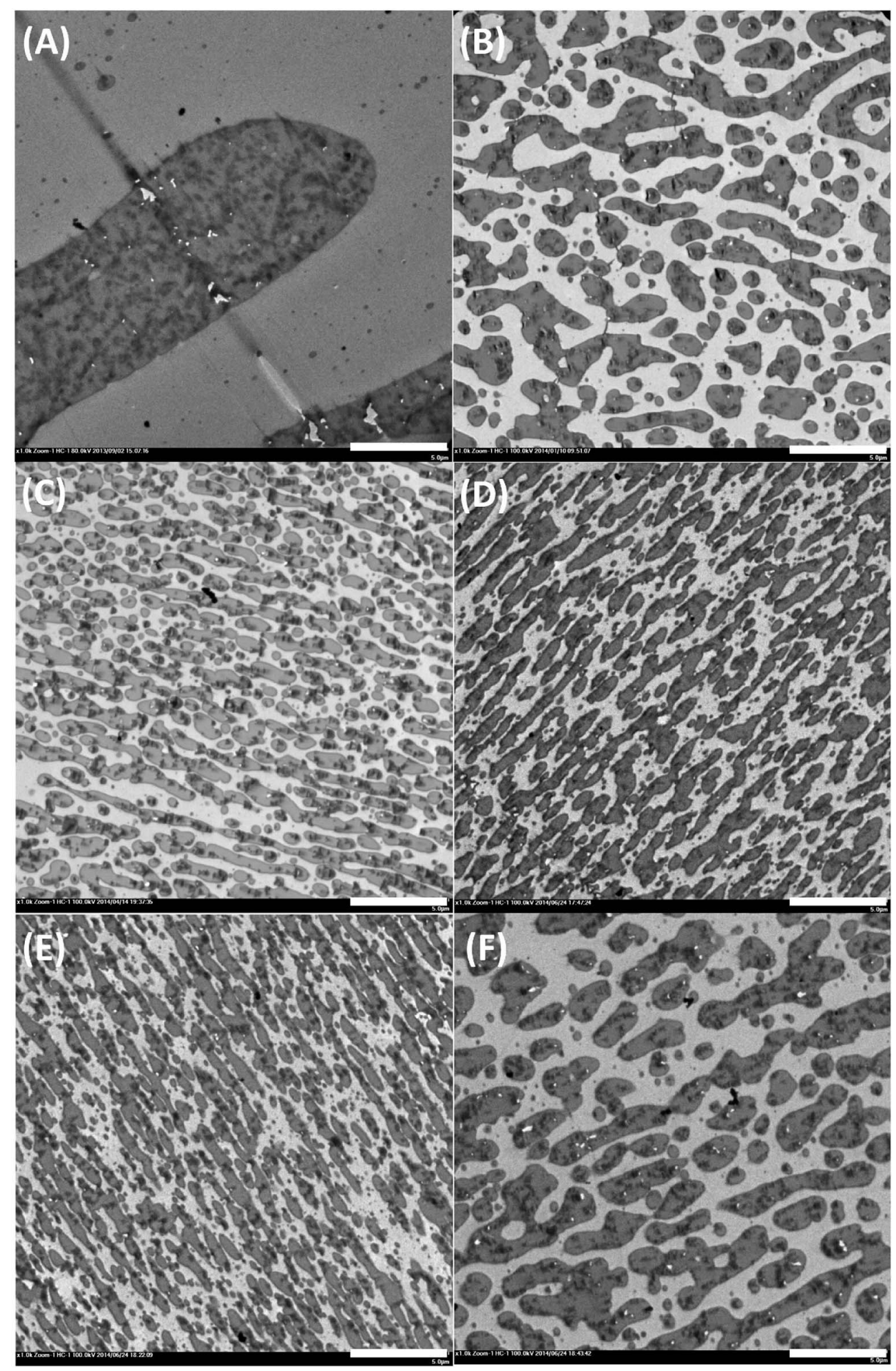

Fig. 3 TEM images of (A) uncompatibilized PLLA/ABS blend and (B-F) compatibilized blends by different blending sequences: (B) PLLA/ABS/RL, (C) PLLA/ABS/RC, (D) (ABS/RL)/PLLA, (E) (ABS/RC)/PLLA, and (F) (PLLA/RC)/ABS. The scale bar is $5 \mu \mathrm{m}$.

Method $1>$ Method 2. Although Method 1 is more convenient compared to the other methods, as shown in Fig. 3, Method 2 can fabricate compatibilized blends with much finer morphologies than Method 1 and 3. This is because in Method 2, the lightly grafted compatibilizers have longer PMMA segments between the two grafted sites, which are able to entangle with the ABS phase more tightly, compared to the other methods. In Method 3 (premixing PLLA and compatibilizers), micelles with sizes from 30-100 $\mathrm{nm}$ are observed in the PLLA phase, as shown in Fig. 4, which derive from the assembly of highly grafted 


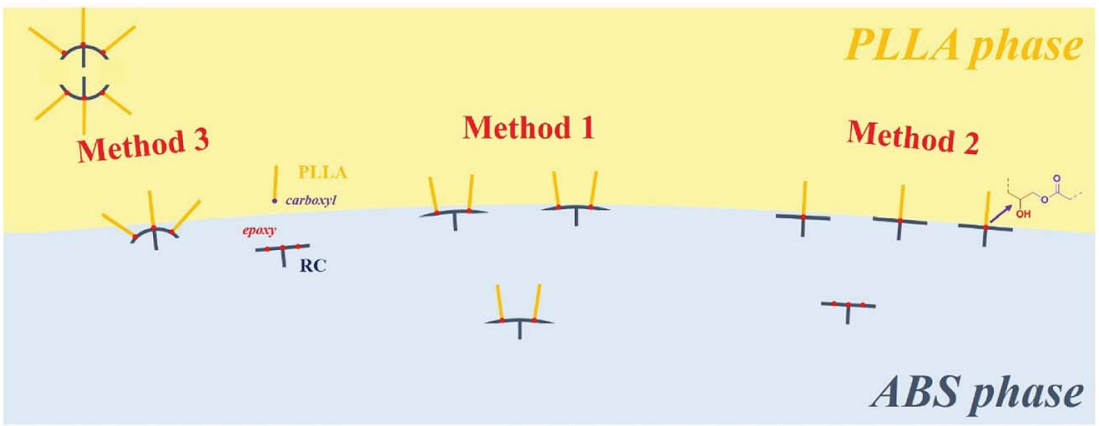

Scheme 1 Interfacial behaviors and distributions of the RC-g-PLLA polymers in PLLA/ABS system, dictated by blending sequences.

compatibilizers. The inner part of the micelles is speculated to be PMMA phase and the shell PLLA phase, because the repulsions among the crowded grafted PLLA chains force the PMMA backbone to bend inward, which tends to form a core-shell structure, as shown in Scheme $1 .^{51}$ Thus, the PMMA segments of the highly grafted compatibilizers are shielded off by the PLLA segments. They have less opportunity to diffuse to the interface to interact with the ABS phase and are more possibly forced to stay in the PLLA phase. The trend of perimeter/area with blending sequences seen in Table 1 , which increases according to the order Method $3<$ Method $1<$ Method 2, can be understandable by now. The most stable grafted polymers at the interface in Method 2 hold the ABS and PLLA phases most tightly, with the inherent PMMA segments penetrating deeply into the SAN phase of ABS and the grafted PLLA segments entangling tightly with the PLLA phase. Greater interfacial interactions also result in greater interfacial frictions under shear field, so the trend of torque values with blending sequences, as mentioned above, is consistent with the trend of perimeter/area.

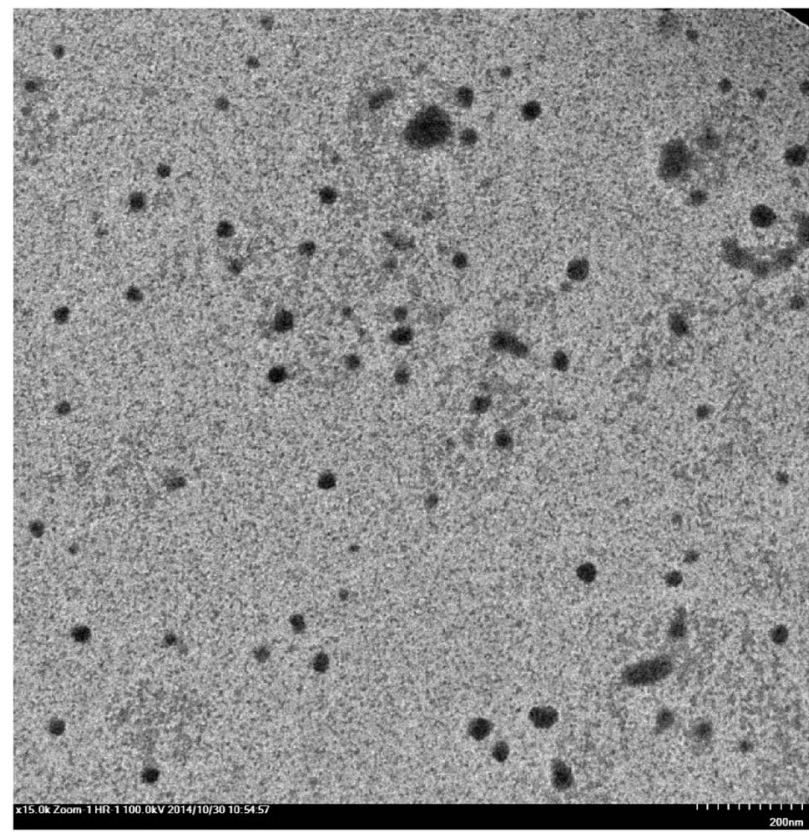

Fig. 4 TEM image of the PLLA/RC (50/3) blend.
It is well known that branched polymers are more prone to segregate to the interface, from the viewpoint of enthalpy, compared to their linear counterparts, because the more concentrated chain ends contribute positively to the enthalpy of the system..$^{50,51}$ On account of this reason, it can be deduced that $\mathrm{RC}$ polymers are more prone to diffuse to the interface compared to RL polymers, especially when produced by Method 2, premixing compatibilizers with ABS phase. In addition, the existence of side chains in RC compatibilizers can provide additional entanglements with the SAN phase of ABS, thus improving the stability of the compatibilizers at the interface compared to the linear compatibilizers without side chains. More concentrated compatibilizers are beneficial for the formation of much finer morphology, which improves the interfacial adhesion and transfers the stress across the interface more efficiently. Therefore, the perimeter/area values of the PLLA/ABS blends compatibilized by RC polymers are higher than those stabilized by RL polymers, and this trend is in accordance with the results of torque values.

\section{Tensile properties}

The stress-strain curves and the corresponding mechanical properties of the PLLA/ABS blends created by different blending

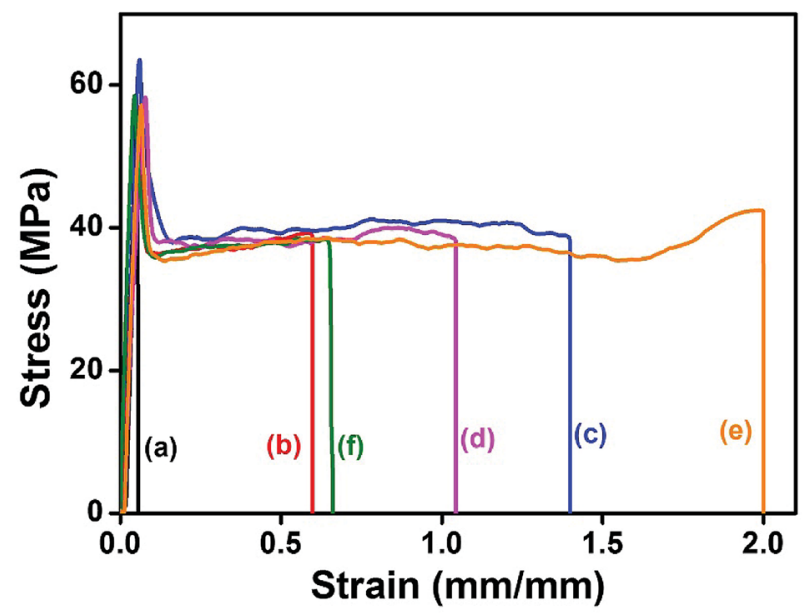

Fig. 5 Representative stress -strain curves of (a) PLLA/ABS, (b) PLLA/ $A B S / R L$, (c) PLLA/ABS/RC, (d) (ABS/RL)/PLLA, (e) (ABS/RC)/PLLA, and (f) (PLLA/RC)/ABS. 
Table 2 Mechanical properties of PLLA, ABS, and uncompatibilized and compatibilized PLLA/ABS blends with different blending sequences

\begin{tabular}{|c|c|c|c|c|}
\hline Sample & $\begin{array}{l}\text { Young's } \\
\text { modulus (GPa) }\end{array}$ & $\begin{array}{l}\text { Yield stress } \\
(\mathrm{MPa})\end{array}$ & $\begin{array}{l}\text { Fracture stress } \\
(\mathrm{MPa})\end{array}$ & $\begin{array}{l}\text { Fracture strain } \\
\left(\mathrm{mm} \mathrm{mm}^{-1}\right)\end{array}$ \\
\hline PLLA & 1.89 & 67 & 57 & 0.07 \\
\hline PLLA/ABS (50/50) & 1.52 & & 50 & 0.03 \\
\hline PLLA/ABS/RL (50/50/3) & 1.48 & 57 & 39 & 0.72 \\
\hline PLLA/ABS/RC (50/50/3) & 1.74 & 64 & 40 & 1.40 \\
\hline$(\mathrm{PLLA} / \mathrm{RC}) / \mathrm{ABS}[(50 / 3) / 50]$ & 1.75 & 59 & 39 & 0.65 \\
\hline
\end{tabular}

sequences are shown in Fig. 5 and summarized in Table 2, respectively. Firstly, comparing those in the same blending method, the PLLA/ABS blends compatibilized with RC polymers have better mechanical properties than those with RL polymers; e.g., the fracture strain of PLLA/ABS/RC is about 2 times higher than that of PLLA/ABS/RL. Secondly, Method 2 (premixing the compatibilizers with the ABS phase) is superior to Method 1 (mixing PLLA, ABS and the compatibilizers simultaneously) in enhancing the mechanical properties of the PLLA/ABS blends; e.g., the fracture strain of (ABS/RC)/PLLA is about 1.3 times higher than that of PLLA/ABS/RC. Thirdly, Method 3 (premixing the PLLA phase with the compatibilizers) deteriorates the mechanical properties of the PLLA/ABS blend, compared to Method 1 and 2. It should be noted that the PLLA/ABS blends compatibilized with RC polymers possess a slightly higher Young's modulus than those with RL polymers. The results of tensile experiments are consistent with the morphology relationship; i.e., the PLLA/ABS blends compatibilized by RC polymers display much finer morphology, regardless of blending sequences. In addition, Method 2 (premixing compatibilizers

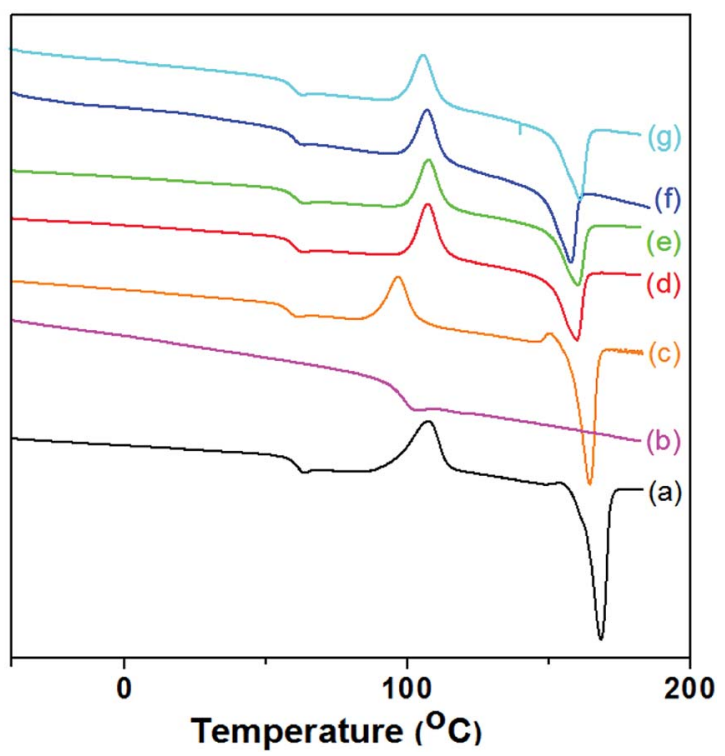

Fig. 6 DSC second heating curves of (a) PLLA, (b) ABS, (c) PLLA/ABS, (d) PLLA/ABS/RL, (e) PLLA/ABS/RC, (f) (PLLA/RC)/ABS and (g) (ABS/RC)/ PLLA.
Table 3 Thermal properties of neat PLLA and uncompatibilized and compatibilized PLLA/ABS blends

\begin{tabular}{lcll}
\hline Samples & $T_{\mathrm{g}}(\mathrm{PLLA})\left({ }^{\circ} \mathrm{C}\right)$ & $T_{\mathrm{m}}(\mathrm{PLLA})\left({ }^{\circ} \mathrm{C}\right)$ & $\Delta H_{\mathrm{m}}\left(\mathrm{J} \mathrm{g}^{-1}\right)$ \\
\hline PLLA & 61.3 & 168.2 & 35.2 \\
ABS & 100.4 & & \\
PLLA/ABS (50/50) & 59.7 & 166.7 & 19.5 \\
PLLA/ABS/RL (50/50/3) & 62.1 & 162.0 & 13.4 \\
PLLA/ABS/RC (50/50/3) & 62.3 & 162.2 & 13.7 \\
(ABS/RL)/PLLA [(50/3)/50] & 61.8 & 163.2 & 13.8 \\
$($ ABS/RC)/PLLA [(50/3)/50] & 62.0 & 163.6 & 13.9 \\
$($ PLLA/RC)/ABS [(50/3)/50] & 61.6 & 155.4 & 10.9
\end{tabular}

with ABS) results in much finer morphologies than the other methods.

\section{Thermal behavior}

The thermal properties of the blend components and the blends were characterized by DSC. The second heating curves and the corresponding results are shown in Fig. 6 and summarized in Table 3, respectively. It can be found that the curves of neat PLLA and PLLA/ABS blends exhibit three apparent transitions upon heating, i.e., the glass transition temperature $\left(T_{\mathrm{g}}\right)$, cold crystallization temperature $\left(T_{\mathrm{cc}}\right)$, and melting temperature $\left(T_{\mathrm{m}}\right)$. The $T_{\mathrm{g}}$ of SAN phase in ABS is almost superimposed with the $T_{\mathrm{cc}}$ of PLLA in the blends, which cannot be observed in the PLLA/ ABS blends. It is obvious that the $T_{\mathrm{g}}$ (PLLA) of the compatibilized PLLA/ABS blends increases a little at higher temperature compared to that of neat PLLA; this can be ascribed to the formation of the compatibilizers at the interface improving the miscibility of PLLA and ABS. Secondly, the $T_{\mathrm{g}}$ (PLLA) of the compatibilized PLLA/ABS blends remains almost constant, regardless of the blending sequences. The evolution of $T_{\mathrm{m}}$ (PLLA) with blending sequences is different from that of $T_{\mathrm{g}}$ (PLLA). It can be observed that Method 3 (premixing PLLA with the compatibilizers) depresses the $T_{\mathrm{m}}$ (PLLA) by $\sim 13{ }^{\circ} \mathrm{C}$ compared to neat PLLA. In addition, the $T_{\mathrm{m}}$ (PLLA) in the compatibilized PLLA/ABS blends by Method 2 has the smallest decrement, compared to the other methods. This means that the blending sequence affects the crystallization of PLLA. As mentioned above, the grafting extent of PLLA with compatibilizers is in the sequence Method $3>$ Method $1>$ Method 2. Thus, the highly grafted polymers formed by Method 3 extensively 
disrupt the integrity of the molecular chains of PLLA, which results in the greatest decrease of $T_{\mathrm{m}}$ (PLLA). ${ }^{52,53}$

\section{Conclusion}

PMMA-type RL and RC polymers are applied as compatibilizers in the PLLA/ABS system using different blending sequences. It was found that the compatibilization efficiency depends not only on the molecular structures of the compatibilizers, but also on the blending sequences. RC polymers with a branched structure are more prone to diffuse to the interface of PLLA/ABS, compared to RL polymers with a linear structure. In addition, the side chains can provide additional entanglements with the SAN phase in ABS, and thus RC polymers are more stable at the interface than RL polymers. Furthermore, by blending ABS with RC polymers firstly, then with PLLA, the obtained RC- $g$-PLLA polymers are lightly grafted molecules. The lightly grafted molecules have longer PMMA segments between two grafted sites; thus, they are able to penetrate more deeply into the ABS phase and entangle with the ABS phase more tightly. Therefore, by blending ABS with RC polymers firstly, then with PLLA, the obtained compatibilized PLLA/ABS blend displays the finest morphology and best mechanical properties in this investigation.

\section{Conflicts of interest}

The authors declare no competing financial interest.

\section{Acknowledgements}

This work was financially supported by the National Natural Science Foundation of China (21244009, 21304026, 21674033), National Key R\&D Program of China (2017YFB0307704) and Zhejiang Provincial Key R\&D Program (2018C01038).

\section{References}

1 R. A. Auras, L. T. Lim, S. E. M. Selke and H. Tsuji, Poly(lactic acid): Synthesis, Structures, Properties, Processing, and Application, John Wiley \& Sons, Inc, 2011.

2 L.-T. Lim, R. Auras and M. Rubino, Processing Technologies for Poly(lactic acid), Prog. Polym. Sci., 2008, 33, 820-852.

3 H. Z. Liu and J. W. Zhang, Research Progress in Toughening Modification of Poly(lactic acid), J. Polym. Sci., Part B: Polym. Phys., 2011, 49, 1051-1083.

4 R. M. Rasal, A. V. Janorkar and D. E. Hirt, Poly(lactic acid) Modifications, Prog. Polym. Sci., 2010, 35, 338-356.

5 L. Yu, K. Dean and L. Li, Polymer Blends and Composites from Renewable Resources, Prog. Polym. Sci., 2006, 31, 576-602.

6 K. S. Anderson, K. M. Schreck and M. A. Hillmyer, Toughening Polylactide, Polym. Rev., 2008, 48, 85-108.

7 J.-B. Zeng, K.-A. Li and A.-K. Du, Compatibilization Strategies in Poly(lactic acid)-Based Blends, RSC Adv., 2015, 5, 3254632565 .
8 K. S. Anderson and M. A. Hillmyer, The Influence of Block Copolymer Microstructure on the Toughness of Compatibilized Polylactide/Polyethylene Blends, Polymer, 2004, 45, 8809-8823.

9 Y. Wang and M. A. Hillmyer, Polyethylene-Poly(L-lactide) Diblock Copolymers: Synthesis and Compatibilization of Poly(L-lactide)/Polyethylene Blends, J. Polym. Sci., Part A: Polym. Chem., 2001, 39, 2755-2766.

10 Y. Xu, J. Loi, P. Delgado, V. Topolkaraev, R. J. McEneany, C. W. Macosko and M. A. Hillmyer, Reactive Compatibilization of Polylactide/Polypropylene Blends, Ind. Eng. Chem. Res., 2015, 54, 6108-6114.

11 H. T. Oyama, Super-Tough Poly(lactic acid) Materials: Reactive Blending with Ethylene Copolymer, Polymer, 2009, 50, 747-751.

12 L. Deng, C. Xu, X. Wang and Z. Wang, Supertoughened Polylactide Binary Blend with High Heat Deflection Temperature Achieved by Thermal Annealing above the Glass Transition Temperature, ACS Sustainable Chem. Eng., 2018, 6, 480-490.

13 Y.-S. He, J.-B. Zeng, G.-C. Liu, Q.-T. Li and Y.-Z. Wang, SuperTough Poly(L-lactide)/Crosslinked Polyurethane Blends with Tunable Impact Toughness, RSC Adv., 2014, 4, 12857-12866.

14 T.-H. Zhao, Y. He, Y.-D. Li, M. Wang and J.-B. Zeng, Dynamic Vulcanization of Castor Oil in a Polylactide Matrix for Toughening, RSC Adv., 2016, 6, 79542-79553.

15 H.-W. Bai, D.-Y. Bai, H. Xiu, H.-L. Liu, Q. Zhang, K. Wang, H. Deng, F. Chen, Q. Fu and F.-C. Chi, Towards HighPerformance Poly(L-lactide)/Elastomer Blends with Tunable Interfacial Adhesion and Matrix Crystallization via Constructing Stereocomplex Crystallites at the Interface, RSC Adv., 2014, 4, 49374-49385.

16 J. Dai, H.-W. Bai, Z. W. Liu, L. Chen, Q. Zhang and Q. Fu, Stereocomplex Crystallites Induce Simultaneous Enhancement in Impact Toughness and Heat Resistance of Injection-Molded Polylactide/Polyurethane Blends, RSC Adv., 2016, 6, 17008-17015.

17 Z. Yin, C. Koulic, H. K. Jeon, C. Pagnoulle, C. W. Macosko and R. Jérôme, Effect of Molecular Weight of the Reactive Precursors in Melt Reactive Blending, Macromolecules, 2002, 35, 8917-8919.

18 C. D. Park, W. H. Jo and M. S. Lee, Effect of Molecular Weight of Functionalized Polystyrene on the Compatibility of Blends of Polyamide 6 and Polystyrene, Polymer, 1996, 37, 30553063.

19 P. Cigana, B. D. Favis and R. Jérôme, Diblock Copolymers as Emulsifying Agents in Polymer Blends: Influence of Molecular Weight, Architecture, and Chemical Composition, J. Polym. Sci., Part B: Polym. Phys., 1996, 34, 1691-1700.

20 D. Hlavatá, J. Hromádková, I. Fortelný, V. Hašová and J. Pulda, Compatibilization Efficiency of Styrene-Butadiene Triblock Copolymers in Polystyrene-Polypropylene Blends with Varying Compositions, J. Appl. Polym. Sci., 2004, 92, 2431-2441.

21 W. Y. Dong, H. T. Wang, F. L. Ren, J. Q. Zhang, M. F. He, T. Wu and Y. J. Li, Dramatic improvement in toughness of 
PLLA/PVDF blends: the effect of compatibilizer architectures, ACS Sustainable Chem. Eng., 2016, 4, 44804489.

22 C. L. Zhang, L. F. Feng, X. P. Gu, S. Hoppe and G. H. Hu, Efficiency of Graft Copolymers as Compatibilizers for Immiscible Polymer Blends, Polymer, 2007, 48, 5940-5949.

23 C. D. Park, W. H. Jo and M. S. Lee, Effect of Molecular Weight of Functionalized Polystyrene on the Compatibility of Blends of Polyamide 6 and Polystyrene, Polymer, 1996, 37, 30553063.

24 S. Kim, J. K. Kim and C. E. Park, Effect of Acrylic Acid Content in Poly(ethylene-ran-acrylic acid) on the Morphology and Mechanical Properties of Poly(ethyleneran-acrylic acid)/Polystyrene Blends Compatibilized by Poly(styrene-ran-glycidyl methacrylate), Polymer, 1997, 38, 2113-2119.

25 N. C. Liu, H. Q. Xie and W. E. Baker, Comparison of the Effectiveness of Different Basic Functional Groups for the Reactive Compatibilization of Polymer Blends, Polymer, 1993, 34, 4680-4687.

26 M. Saleem and W. E. Baker, In Situ Reactive Compatibilization in Polymer Blends: Effects of Functional Group Concentrations, J. Appl. Polym. Sci., 1990, 39, 655-678.

27 P. Martin, C. Gallez, J. Devaux, R. Legras, L. Leemans, M. van Gurp and M. van Duin, Reactive Compatibilization of Blends of Polybutyleneterephthalate with Epoxide-containing Rubber. The Effect of the Concentrations in Reactive Functions, Polymer, 2003, 44, 5251-5262.

$28 \mathrm{H}$. K. Jeon and J. K. Kim, The Effect of the Amount of In situ Formed Copolymers on the Final Morphology of Reactive Polymer Blends with an In situ Compatibilizer, Macromolecules, 1998, 31, 9273-9280.

29 J. K. Kim, D. K. Yi, H. K. Jeon and C. E. Park, Effect of the Functional Group Inhomogeneity of an In situ Reactive Compatibilizer on the Morphology and Rheological Properties of Immiscible Polymer Blends, Polymer, 1999, 40, 2737-2743.

30 W. Hale, H. Keskkula and D. R. Paul, Effect of Crosslinking Reactions and Order of Mixing on Properties of Compatibilized PBT/ABS Blends, Polymer, 1999, 40, 36653676.

31 J. D. Lee and S. M. Yang, Effects of Mixing Procedures on Properties of Compatibilized Polypropylene/Nylon 6 Blends, Polym. Eng. Sci., 1995, 35, 1821-1833.

32 B. K. Kim, Y. M. Lee and H. M. Jeong, Physical Properties of ABS/SMA/Nylon-6 Ternary Blends: Effect of Blending Sequence, Polymer, 1993, 34, 2075-2080.

33 L. D. C. Castro, A. D. Oliveira, M. Kersch, V. Altstädt and L. A. Pessan, Effects of Mixing Protocol on Morphology and Properties of PA6/ABS Blends Compatibilized with MMA-MA, J. Appl. Polym. Sci., 2016, 133, 43612.

$34 \mathrm{M}$. Wu, K. Wang, Q. Zhang and Q. Fu, Manipulation of Multiphase Morphology in the Reactive Blending System OBC/PLA/EGMA, RSC Adv., 2015, 5, 96353-96359.

35 Q. Wang, Y. Jiang, L. Li, P. Wang, Q. Yang and G. Li, Mechanical Properties, Rheology, and Crystallization of Epoxy-Resin-Compatibilized Polyamide 6/Polycarbonate
Blends: Effect of Mixing Sequences, J. Macromol. Sci., Part B: Phys., 2012, 51, 96-108.

36 Y. Peng, W. Guo, P. Zhu and C. Wu, Structures and Properties of Ternary Blends of Recycled Poly(ethylene terephthalate)/Bisphenol-A Polycarbonate/(E/nBA/GMA), $J$. Appl. Polym. Sci., 2008, 109, 483-491.

37 P. Martin, C. Maquet, R. Legras, C. Bailly, L. Leemans, M. van Gurp and M. van Duin, Particle-in-Particle Morphology in Reactively Compatibilized Poly(butylene terephthalate)/ Epoxide-containing Rubber Blends, Polymer, 2004, 45, 3277-3284.

38 W. Dong, X. Cao and Y. Li, High-performance Biosourced Poly(lactic acid)/Polyamide 11 Blends with Controlled Salami Structure, Polym. Int., 2014, 63, 1094-1100.

$39 \mathrm{~J} . \mathrm{Wu}, \mathrm{P}$. Xue and Y.-W. Mai, Effect of Blending Sequence on the Morphology and Impact Toughness of Poly(ethylene terephthalate)/Polycarbonate Blends, Polym. Eng. Sci., 2000, 40, 786-797.

40 B. Lin, U. Sundararaj and P. Guegan, Effect of Mixing Protocol on Compatibilized Polymer Blend Morphology, Polym. Eng. Sci., 2006, 46, 691-702.

41 H.-H. Chang, J.-S. Wu and F.-C. Chang, Reactive Compatibilization of ABS/Nylon 6,6 Blends: Effects of Reactive Group Concentration and Blending Sequence, $J$. Polym. Res., 1994, 1, 235-245.

42 S. Cimmino, F. Coppola, L. D' Orazio, R. Greco, G. Maglio, M. Malinconico, C. Mancarella, E. Martuscelli and G. Ragosta, Ternary Nylon-6/Rubber/Modified Rubber Blends: Effect of the Mixing Procedure on Morphology, Mechanical and Impact Properties, Polymer, 1986, 27, 1874-1884.

43 R. A. Kudva, H. Keskkula and D. R. Paul, Properties of Compatibilized Nylon 6/ABS Blends: Part II. Effects of Compatibilizer Type and Processing History, Polymer, 2000, 41, 239-258.

44 S. Paul and D. D. Kale, Blends of Acrylonitrile-ButadieneStyrene/Waste Poly (ethylene terephthalate) Compatibilized by Styrene Maleic Anhydride, J. Appl. Polym. Sci., 2001, 80, 2593-2599.

45 W. R. Hale, L. A. Pessan, H. Keskkula and D. R. Paul, Effect of Compatibilization and ABS Type on Properties of PBT/ABS Blends, Polymer, 1999, 40, 4237-4250.

46 W. Y. Dong, H. T. Wang, M. F. He, F. L. Ren, T. Wu, Q. R. Zheng and Y. J. Li, Synthesis of Reactive Comb Polymers and Their Applications as a Highly Efficient Compatibilizer in Immiscible Polymer Blends, Ind. Eng. Chem. Res., 2015, 54, 2081-2089.

47 J. A. Galloway, M. D. Montminy and C. W. Macosko, Image Analysis for Interfacial Area and Cocontinuity Detection in Polymer Blends, Polymer, 2002, 43, 4715-4722.

$48 \mathrm{~S}$. Wu, Formation of Dispersed Phase in Incompatible Polymer Blends: Interfacial and Rheological Effects, Polym. Eng. Sci., 1987, 27, 335-343.

49 P. Pötschke and D. R. Paul, Formation of Co-Continuous Structures in Melt-Mixed Immiscible Polymer Blends, $J$. Macromol. Sci., Polym. Rev., 2003, 43, 87-141. 
50 N. Z. Qureshi, M. Rogunova, E. V. Stepanov, G. Capaccio, A. Hiltner and E. Baer, Self-Adhesion of Polyethylene in the Melt. 2. Comparison of Heterogeneous and Homogeneous Copolymers, Macromolecules, 2001, 34, 3007-3017.

51 D. T. Wu and G. H. Fredrickson, Effect of Architecture in the Surface Segregation of Polymer Blends, Macromolecules, 1996, 29, 7919-7930.

52 C. Sailer and U. A. Handge, Reactive Blending of Polyamide 6 and Styrene-Acrylonitrile Copolymer: Influence of Blend
Composition and Compatibilizer Concentration on Morphology and Rheology, Macromolecules, 2008, 41, 42584267.

53 V. Ojijo, S. S. Ray and R. Sadiku, Toughening of Biodegradable Polylactide/Poly(butylene succinate-coadipate) Blends via In situ Reactive Compatibilization, ACS Appl. Mater. Interfaces, 2013, 5, 4266-4276. 